\title{
Electrophysiological study of peroneal palsy
}

\author{
NAUNIHAL SINGH ${ }^{1}$, FRIEDRICH BEHSE, AND FRITZ BUCHTHAL \\ From the Laboratory of Clinical Neurophysiology, University Hospital (Rigshospital) \\ and the Institute of Neurophysiology, University of Copenhagen, Copenhagen, Denmark
}

SYNOPSIS The diagnostic yield of different electrophysiological criteria was examined to establish whether a peroneal palsy was due to compression of the nerve in the region of the capitulum fibulae. Slowing of sensory conduction along the segment of the nerve across the capitulum fibulae localized the lesion in $64 \%$ of 47 consecutive patients with a history indicating or suggesting compression of the nerve in the vicinity of the capitulum fibulae and there were no false positive findings in 18 patients whose peroneal palsy was not due to compression at the capitulum fibulae. In $20 \%$ of the patients with slowing along the segment across the capitulum, conduction velocity was normal when measured from the superior retinaculum to the popliteal fossa. Slowing along motor fibres (m extensor digitorum brevis) localized the site of the lesion in one-third of the patients. Differences if amplitude and in split-up of the sensory responses recorded in the popliteal fossa as compared with those recorded distal to the capitulum fibulae were of limited diagnostic value because of man柯 false positive findings among patients whose peroneal palsy was not due to compression of the nervo at the capitulum fibulae.

Though doubt often arises with respect to the site of the lesion in peroneal palsy, only few attempts are reported in the literature to localize the lesion by electrophysiological methods. Gilliatt et al. (1961) found in four patients slowing and diminished amplitudes of mixed nerve action potentials evoked at the ankle and recorded at the neck of the fibula. Gassel and Trojaborg (1964) interpreted the slower velocity in motor fibres to the extensor digitorum brevis along the segment of the nerve in the leg as compared with that along the nerve in the thigh to indicate a lesion of the peroneal nerve in the vicinity of the capitulum fibulae. Behse and Buchthal (1971) determined sensory and motor conduction along a $10 \mathrm{~cm}$ length of the peroneal nerve across the capitulum fibulae and compared them with the velocity in the segment distal to the capitulum fibulae along the leg. This procedure permits a lesion at the capitulum to be localized with greater precision, and mild involve-

1 On leave from the All-India Institute of Medical Sciences, New Delhi, India, working with a fellowship from the Danish International Development Agency. ment can be recognized by excluding the stretci of nerve which usually is less affected or norma? The diagnostic yield can be increased by examine ing motor and sensory fibres separately. The same procedure has previously been applied to $f$ localize a lesion of the ulnar nerve in the cubital sulcus (Payan, 1969), of the radial nerve proximal to the elbow (Trojaborg, 1970), and of the median nerve at the wrist (Buchthal and Rosenfalck, 1971a; Buchthal et al., 1974). To obtain the best possible resolution of the small sensory potentials and to define the site of recording and stimulation as accurately as possible needle electrodes were placed near the nerve.

The purpose of the study presented in this report was to evaluate the diagnostic yield of electrophysiological procedures and criteria available to localize a lesion of the peroneal nerve in the region of the capitulum fibulae. For this purpose, findings were compared in consecutive patients with peroneal palsy due to or presumably due to compression of the nerve at the capitulum fibulae with findings in patients in whom there was evidence that the peroneal palsy was due to other causes. 


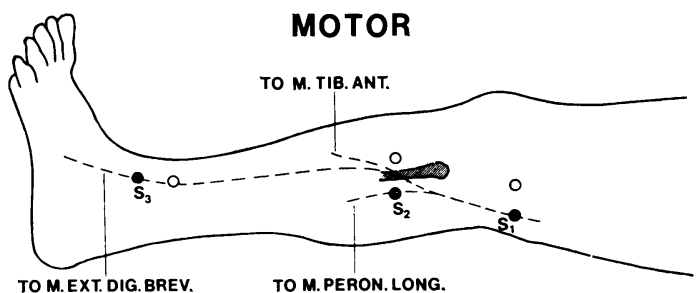

TO M.EXT. DIG. BREV. TO M.PERON. LONG.

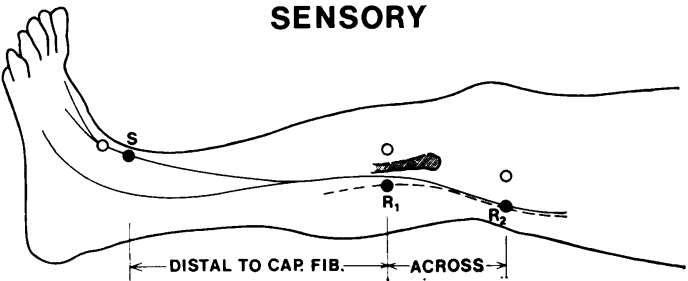

FIG. 1. Placement of near-nerve (O) and remote $(O)$ electrodes for measurement of motor and sensory conduction. Sensory: S, stimulus to medial branch of superficial peroneal nerve at superior extensor retinaculum. Recording from sensory fibres of superficial peroneal nerve $2 \mathrm{~cm}$ distal to capitulum fibulae $\left(\mathbf{R}_{1}\right)$ and in the popliteal fossa $\left(\mathrm{R}_{2}\right)$. Motor: stimulus to common peroneal nerve in popliteal fossa $\left(\mathrm{S}_{1}\right)$, and $2 \mathrm{~cm}$ distal to the capitulum fibulae $\left(\mathrm{S}_{2}\right)$; to deep peroneal nerve at ankle $\left(\mathrm{S}_{3}\right)$. Recording from $m$. tibialis anterior, $m$. peroneus longus, and $m$. extensor digitorum brevis.

\section{METHOD}

SENSORY CONDUCTION The procedure employed to study conduction along the superficial peroneal nerve has been described (Behse and Buchthal, 1971). In brief:

Stimulation Rectangular current pulses of 8-12 mA, $0.2 \mathrm{~ms}$ in duration, were applied via needle electrodes to the nerve at the superior extensor retinaculum (Fig. 1). In normal nerve this current strength is 10 to 20 times the threshold of the sensory potential. Absence of an action potential of the extensor digitorum brevis muscle ascertained that the stimulus was confined to the superficial peroneal nerve.

Recording Sensory potentials were recorded via a needle electrode ( $3 \mathrm{~mm}$ bared tip) placed near the nerve, 1-2 cm distal to the capitulum fibulae and another at a distance of at least 9.5 and at most $11.5 \mathrm{~cm}$ proximal to the capitulum fibulae measured on the fully extended leg. The remote electrode was placed at a transverse distance of $3-4 \mathrm{~cm}$ at the level of the near-nerve electrode (Fig. 1). At both sites of recording the electrode was adjusted near the peroneal nerve using the threshold of the potential evoked in the long peroneal muscle as a gauge (stimulus current $<0.8 \mathrm{~mA}$ ). Five hundred to 1,000 sensory responses were averaged electronically together with a calibration signal; $0.03 \mu \mathrm{V}$ could be identified; to obtain the same resolution at different latencies (40-60 $\mu$ s per point) a delay of 3-10 ms was used between stimulus and sampling (Buchthal and Rosenfalck, 1966, 1971b). The maximum sensory conduction velocity was calculated from the latency to the first positive peak of the sensory potential. The velocity from the point distal to the capitulum fibulae to the popliteal fossa was calculated from the difference in latencies recorded at the two sites. The amplitude of the potential was measured peak-topeak.

MOTOR CONDUCTION The near-nerve electrodes placed in the popliteal fossa and distal to the capitulum fibulae were used to stimulate motor nerve fibres (Fig. 1). In addition, electrodes were placed near the deep peroneal nerve at the ankle. The stimulating current was $6-10 \mathrm{~mA}(0 \cdot 2 \mathrm{~m} / \mathrm{s}$ in duration), five to 10 times the threshold of the muscle action potential. Muscle action potentials were recorded via concentric needle electrodes placed in the endplate zone of the anterior tibial, long peroneal, and extensor digitorum brevis muscles. Amplitudes were measured peak-to-peak, and latencies to the onset of the initial deflection of the muscle action potential. Latencies from the point distal to the capitulum fibulae to the anterior tibial and long peroneal muscle were compared with latencies obtained in normal nerve at the same distance of conduction. The latency from ankle to the extensor digitorum brevis muscle was corrected to a standard distance of $9 \mathrm{~cm}$ by means of the velocity along the nerve from distal to the capitulum fibulae to ankle (Wagner and Buchthal, 1972).

AGE Findings in sensory and motor nerves in patients were compared with those in normal nerves matched for age.

ABBREVIATIONS Velocity distal to the capitulum fibulae denotes the sensory velocity from retinaculum superior to $2 \mathrm{~cm}$ distal to the capitulum fibulae and the motor velocity from $2 \mathrm{~cm}$ distal to the capitulum fibulae to ankle (Fig. 1). Velocity across denotes the sensory and motor velocity in the segment of the nerve between $2 \mathrm{~cm}$ distal to the capitulum fibulae and fossa poplitea (Fig. 1).

TEMPERATURE An infra-red heating element (500 W) was placed $20 \mathrm{~cm}$ above the extremity. It was con- 

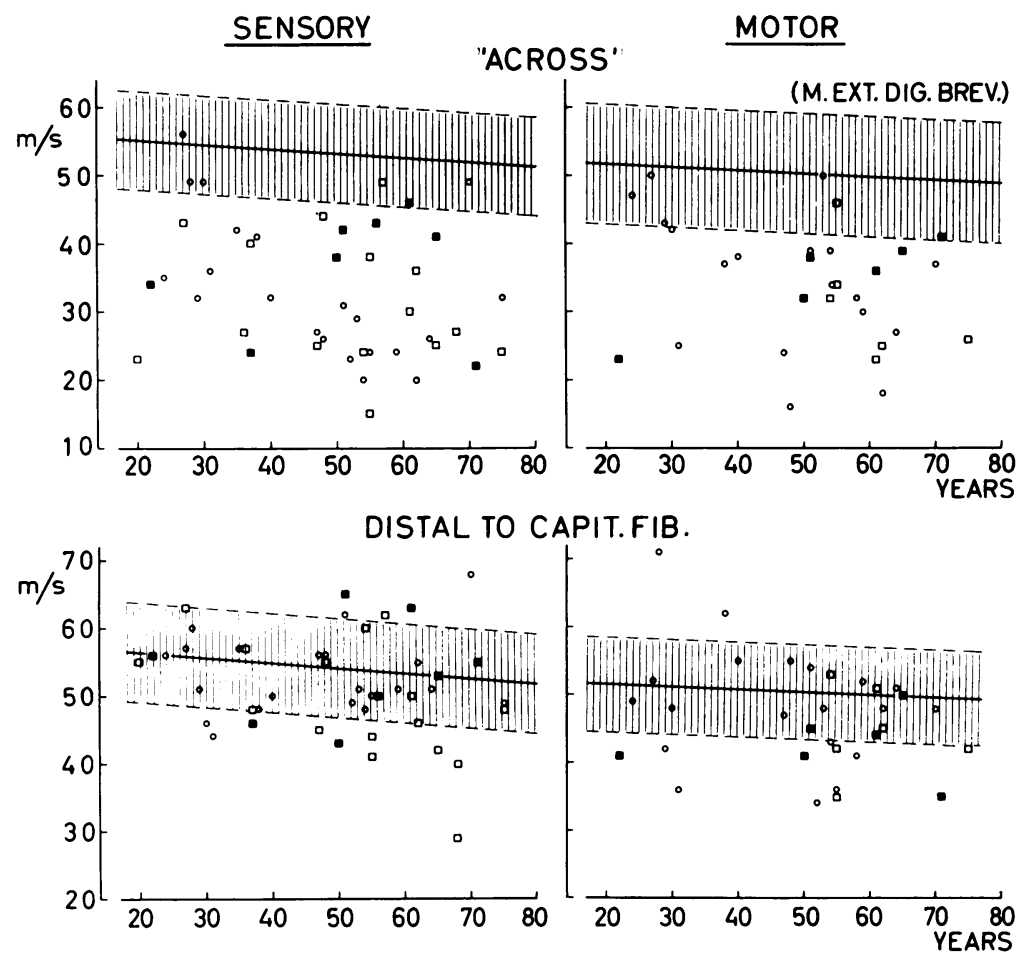

FIG. 2. Conduction velocity along the peroneal nerve as a function of age. Above: across the region of the capitulum fibulae. Below: distal to the capitulum fibulae. Left: sensory conduction velocity, stimulus applied to the nerve at the superior retinaculum (45 patients). Right: motor conduction velocity to the extensor digitorum brevis muscle (31 patients). Patients with a history indicating $(\bigcirc)$ or suggesting $(\square)$ compression of the nerve in the region of the capitulum fibulae. The full symbols represent patients with local compression in addition to systemic neuropathy. The full line gives the average of 35 (sensory conduction) and 32 (motor conduction) normal nerves. The dashed lines represent the $95 \%$ confidence limits.

trolled by a thermocouple on the leg and ensured a temperature of $36-37^{\circ} \mathrm{C}$, corresponding to $34^{\circ}-35^{\circ} \mathrm{C}$ near the nerve.

ELECTROMYOGRAPHY M. tibialis anterior, m. extensor digitorum brevis, and $\mathrm{m}$. peroneus longus were examined. When there was suspicion of root compression or systemic neuropathy other muscles of the legs or hands were examined as well.

Findings were characterized by (1) the pattern of activity during full effort, (2) the amplitude of its envelope curve; (3) the number of sites in which fibrillation potentials and positive sharp waves were recorded outside the endplate zone, (4) the mean potential duration of at least 20 randomly sampled motor units potentials, and (5) the incidence of poly- phasic potentials. Findings were evaluated by comparison with normal muscles matched for age (Buchthal, 1957).

\section{SUBJECTS AND PATIENTS}

Data on normal sensory conduction velocity along the superficial peroneal nerve, on motor conduction along the superficial and deep peroneal nerve, as well as on amplitude and shape of sensory potentials and of evoked muscle action potentials were obtained in 74 subjects without history, signs, or symptoms of neuromuscular disease. They were 16 to 72 years old. In 33 , conduction velocity was determined along the segment distal to and 'across' the capitulum fibulae. 
The 77 patients were all those referred for investigation of peroneal palsy. They were in a neurological or neurosurgical ward. Half were 40 to 60 years old, one-quarter 20 to 40 , and one-quarter more than 60 years old. Based on history, clinical signs and symptoms, radiographic and laboratory findingsbut not electrophysiological findings-65 patients were classified in three groups:

GROUP I Twenty-three patients with a definite history of local compression of the peroneal nerve at the capitulum fibulae ('crossed legs' palsy, palsy due to squatting).

GROUP II Twenty-four patients, whose history suggested or was compatible with local compression of the peroneal nerve at the capitulum fibulae; eight of these patients had signs and symptoms of systemic neuropathy.

\section{SENSORY}

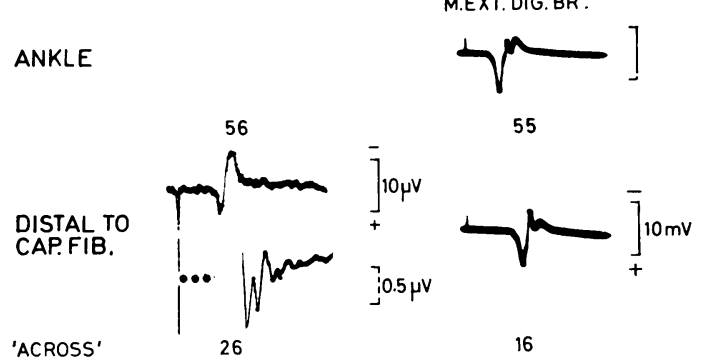

POPLIT FOSSA

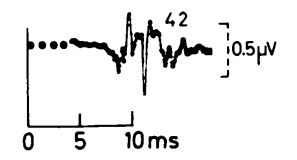

MOTOR M.EXT. DIG.BR.

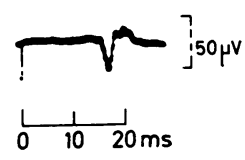

FIG. 3. Sensory and motor conduction along the peroneal nerve. Conduction 'ACROSs' was severely slowed (sensory: $26 \mathrm{~m} / \mathrm{s}$; motor: $16 \mathrm{~m} / \mathrm{s}$ ) and normal in the segment of the nerve distal to the capitulum fibulae (sensory: $56 \mathrm{~m} / \mathrm{s}$; motor: $55 \mathrm{~m} / \mathrm{s}$ ). Conduction from the superior retinaculum to the popliteal fossa was $42 \mathrm{~m} / \mathrm{s}$. The sensory potential distal to the capitulum was recorded both at low gain and at the same high gain as the potential in the popliteal fossa. The sensory potentials were recorded by electronic

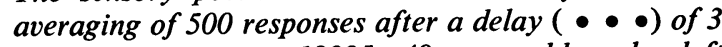
and $4 \mathrm{~ms}$. Patient 18095, 48 year old male, left peroneal palsy after sitting with crossed legs for three to four hours, examined 20 days after the onset of the palsy. Motor and sensory signs and symptoms were confined to the left peroneal nerve.
The patients of groups I and II were examined three weeks to one year after the onset of the palsy, half within 10 weeks. Two-thirds had a severe palsy (anterior tibial and long peroneal muscles graded as 3 or less, Medical Research Council, 1943) and onethird moderate or mild involvement (graded as 4 or more).

Of the patients, $80 \%$ had weakness and wasting as well as diminished sensitivity to touch and pin-prick in the distribution of the peroneal nerve. Four had purely motor and four purely sensory signs and symptoms. Twelve patients complained of pain.

GROUP III Eighteen patients in whom the clinical course, laboratory, and radiographic studies demonstrated causes of the peroneal palsy other than local compression at the capitulum fibulae: nine had evidence of lumbar root compression or of compression of the spinal cord; two of a supranuclear affection; two had motor neurone disease; one a mononeuritis multiplex; two a lesion of the sciatic nerve, one had sequelae after phlebitis, and one after repeated foot distortions.

Half the patients were examined six months or longer after the onset of signs and symptoms. Half had severe involvement (anterior tibial and long peroneal muscles graded as 3 or less) and half moderate or mild involvement (graded as 4 or more). Two-thirds of the patients had sensory as well as motor signs and symptoms in the distribution of the peroneal nerve, one-third had weakness and wasting without sensory loss. Three complained of pain.

NOT INCLUDED IN THE STUDY Twelve patients, in whom the peroneal palsy was due to fracture, when the site of the lesion was evident.

\section{RESULTS}

CONDUCTION VELOCITY ALONG NORMAL NERVE In normal subjects motor and sensory conduction velocity and their scatter were the same along the segment distal to the capitulum fibulae as in the segment across. In 50 year old normal subjects the sensory conduction velocity averaged $54 \mathrm{~m} / \mathrm{s}$ with a $95 \%$ confidence limit of $47 \mathrm{~m} / \mathrm{s}$, the motor conduction velocity (m. extensor digitorum brevis) $51 \mathrm{~m} / \mathrm{s}$ with a lower limit of $44 \mathrm{~m} / \mathrm{s}$ (Fig. 2). In the individual normal subject the maximum velocity across the capitulum fibulae may be as much as $10 \mathrm{~m} / \mathrm{s}$ slower or faster than the velocity distal to it (Fig. 4). Criteria for recognizing slowing along motor and 


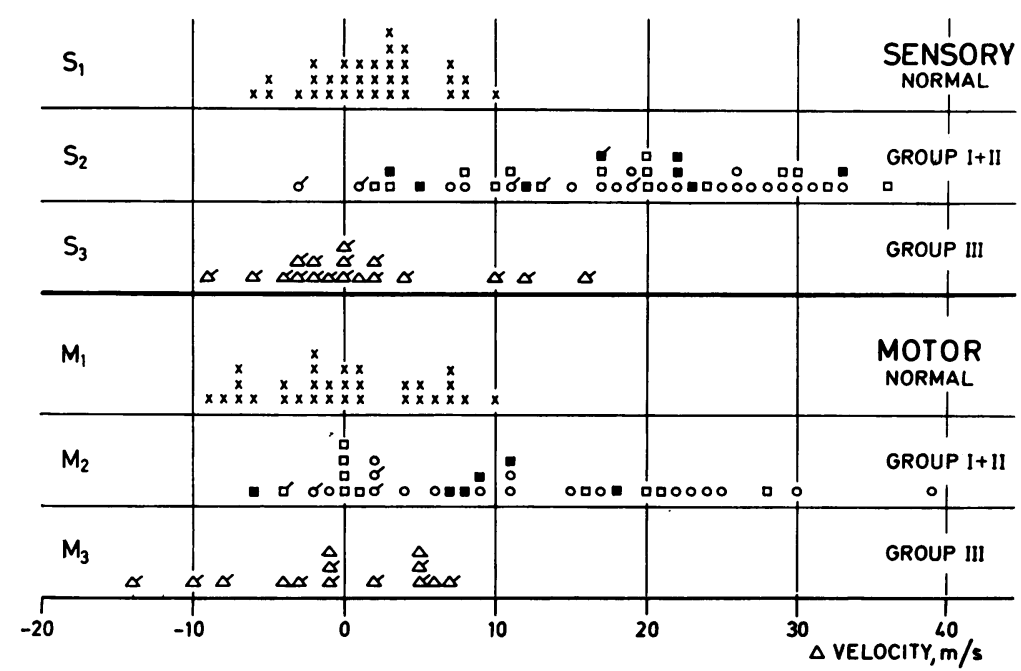

FIG. 4. Conduction velocity along the segment of the nerve distal to the capitulum fibulae minus the velocity across in peroneal palsy and in normal nerve $(\triangle$ velocity $\mathrm{m} / \mathrm{s})$. Each symbol refers to one nerve. A difference of $>10 \mathrm{~m} / \mathrm{s}$ was considered abnormal. $\mathrm{S}_{1}, \mathrm{~S}_{2}, \mathrm{~S}_{3}$ : sensory fibres (superficial peroneal nerve). $\mathrm{M}_{1}, \mathrm{M}_{2}, \mathrm{M}_{3}$ : motor fibres to the extensor digitorum brevis muscle. $(x)$ normal nerves, $(\bigcirc)$ nerves from patients with a history indicating, or ( $\square$ ) suggesting compression of the nerve in the region of the capitulum fibulae (groups I and II); $(\triangle)$ patients with clinical, laboratory, and radiological evidence that the peroneal palsy was due to causes other than local compression at the capitulum fibulae. The filled symbols indicate evidence of systemic neuropathy. The bars at the symbols denote that the conduction velocity across was normal (within the $95 \%$ confidence limit).

sensory fibres localized to the segment of the nerve 'across' were then:

1. The velocity across the capitulum fibulae was slowed to below the normal range and the velocity along the segment distal to the capitulum fibulae was within the normal range $(95 \%$ confidence limit).

2. The conduction velocity across the capitulum fibulae was slower than that distal to it by more than $10 \mathrm{~m} / \mathrm{s}$, though both values were within the normal range or the velocity was slightly slowed distal to the capitulum fibulae.

SENSORY CONDUCTION IN PERONEAL PALSY Patients of groups I and II In 38 of 47 patients $(81 \%)$, with a history that indicated or suggested compression of the nerve in the region of the capitulum fibulae, localized slowing manifested itself in three ways: (1) slowing across and normal conduction velocity distal to the capitulum fibulae (30 patients, Figs 2, 3); (2) conduction velocity across more than $10 \mathrm{~m} / \mathrm{s}$ slower than distal but within the normal range (four patients, Fig. 4); (3) slowing along both segments but more severe across than distal (difference $>10 \mathrm{~m} / \mathrm{s}$, four patients, Fig. 2).

Slowing localized to the segment across may remain hidden, when conduction velocity is determined only from the superior retinaculum to the popliteal fossa, since this portion of the nerve contains a large stretch with normal conduction. In 10 patients conduction velocity from retinaculum to the popliteal fossa was normal, although it was slowed across (six patients) or the velocity across was more than $10 \mathrm{~m} / \mathrm{s}$ slower than distal to the capitulum fibulae.

Slowing along the segment distal to the capitulum fibulae was due to loss of fast con- 0 ducting nerve fibres, as indicated by the linear $N$ 


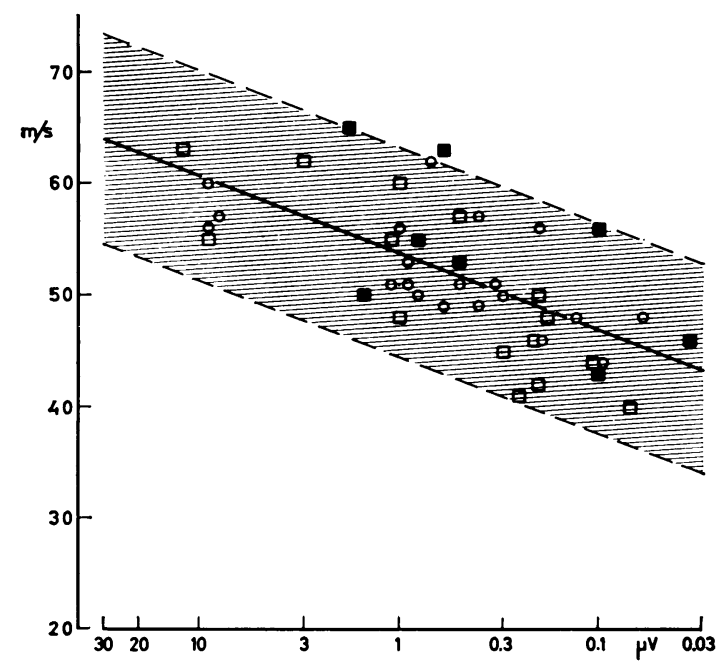

FIG. 5. Sensory conduction velocity (v) along the superficial peroneal nerve from retinaculum superior to distal to the capitulum fibulae as a function of decreasing amplitude (a, log scale) of the sensory potential. Forty-four patients with a history indicating $(\bigcirc)$ or suggesting $(\square)$ compression of the nerve in the region of the capitulum fibulae. The regression line (full line) is given by $v(\mathrm{~m} / \mathrm{s})=53.8+6.9 \times \log a(\mu V)$, the $95 \%$ confidence limits by the dashed lines $(S D$ $4.7 \mathrm{~m} / \mathrm{s}$ ). The relation indicates that the decrease in conduction velocity is due to loss of fast-conducting fibres. decrease in conduction velocity with the logarithm of amplitude (Fig. 5).

In nine patients the lesion could not be localized: in five slowing was as pronounced distal to the capitulum fibulae as across, in one patient sensory conduction was normal; in three the action potential in the popliteal fossa could not be distinguished from noise.

Sensory slowing was as pronounced three weeks as 40 weeks after the onset of signs and symptoms. It tended to be less in patients studied after one year or later. The incidence of slowing in sensory conduction was the same whether the peroneal palsy was mild or severe, but severe slowing occurred more frequently when the force of the anterior tibial or long peroneal muscles was graded as 3 or less.

Patients of group III In 17 of the 18 patients in whom compression at the capitulum fibulae was unlikely as the cause of the peroneal palsy, conduction was normal or borderline across and distal to the capitulum fibulae. However, in two the velocity across was more than $10 \mathrm{~m} / \mathrm{s}$ slower than along the distal segment (Fig. 4). In one patient conduction was slowed in both segments of the nerve.

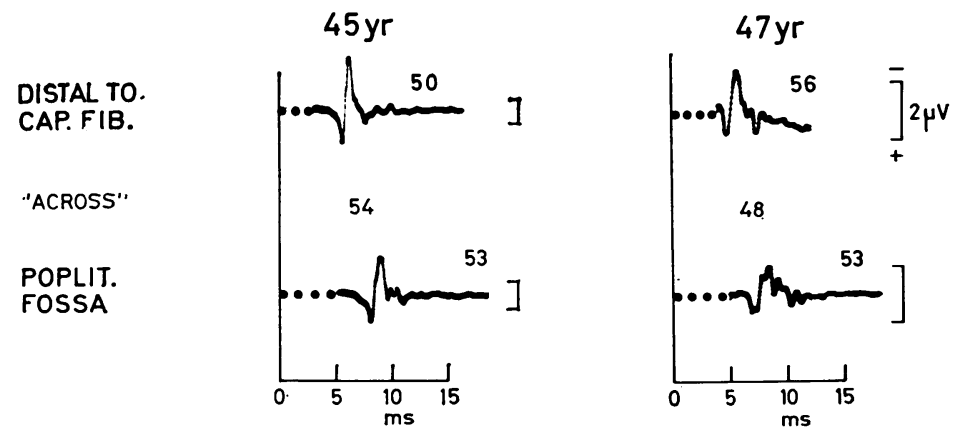

FIG. 6. Sensory potentials of the superficial peroneal nerve recorded $2 \mathrm{~cm}$ distal to the capitulum fibulae and in the popliteal fossa in two normal subjects, 45-47 years old. The numbers above the traces give conduction velocities $(\mathrm{m} / \mathrm{s})$ from superior extensor retinaculum to distal to the capitulum fibulae (upper traces) and to the popliteal fossa (lower traces). 'ACROSS': conduction velocity $(\mathrm{m} / \mathrm{s})$ calculated from distal to the capitulum fibulae to the popliteal fossa. $\bullet \bullet \bullet:$ delay of 3-5 ms introduced after the stimulus before electronic averaging of 500 responses. 


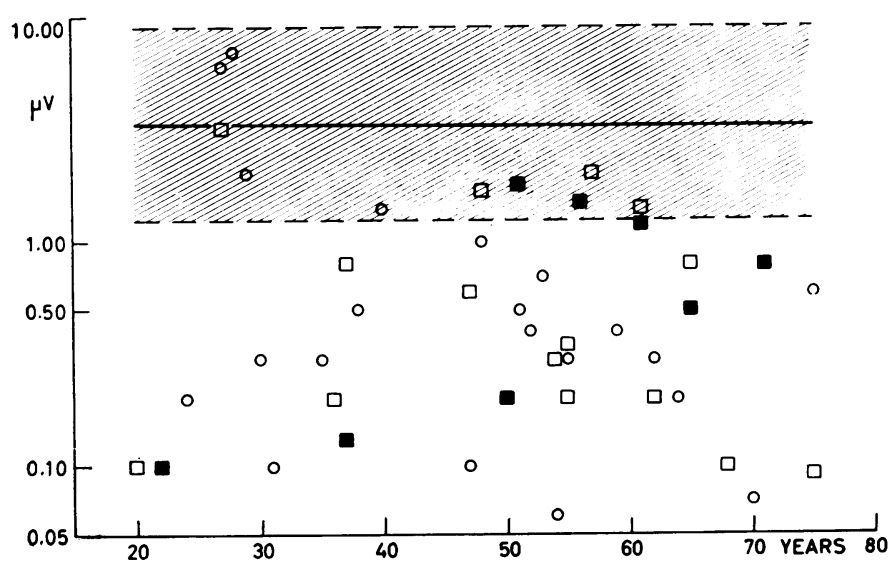

FIG. 7. Amplitude (log scale) of the sensory potential of the superficial peroneal nerve recorded in the fossa poplitea as a function of age. Stimulus applied to the nerve at the superior retinaculum. Forty-four patients with a history indicative $(\bigcirc)$ or suggestive $(\square)$ of compression in the region of the capitulum fibulae. The full symbols represent eight patients with local compression in addition to systemic neuropathy. The full line gives the average of 36 normal nerves, the dashed lines the $95 \%$ confidence limits.
AMPLITUDE AND SHAPE OF SENSORY POTENTIALS Normal nerves In subjects 50 years of age, the amplitude of the sensory potential recorded distal to the capitulum fibulae and in the popliteal fossa averaged $3 \mu \mathrm{V}$ (Fig. 7). The lower 95\% confidence limit was $0 \cdot 5-1 \mu \mathrm{V}$. Considering individual nerves, in half the amplitude recorded distal to the capitulum fibulae was $30-100 \%$ greater than when recorded in the popliteal fossa; in one-third amplitudes were equal, and in $20 \%$ the amplitude distal to was smaller than in the popliteal fossa.

With one exception, the main phase of the sensory potential recorded distal to and in the popliteal fossa was split up into at most six components (Figs 6 and 8). The duration of the potential was $30-50 \%$ longer in the popliteal fossa than distal to it.

In patients with indication or suggestion of compression of the peroneal nerve in the region of the capitulum fibulae (groups I and II), $70 \%$ of the potentials recorded distal to and $80 \%$ of the potentials recorded in the popliteal fossa had amplitudes below the $95 \%$ confidence limit of normal; half the potentials were diminished to $0.3 \mu \mathrm{V}$ or less (Fig. 7). The amplitude was however a poor indicator of the site of the lesion: only $15 \%$ of the potentials recorded distally were at least 2.5 times greater than potentials recorded in the popliteal fossa.

In patients of group III, in whom compression in the region of the capitulum fibulae was unlikely, amplitudes of the sensory potentials were usually normal. In four patients the amplitude was diminished proximal as well as distal to the capitulum fibulae.

In three patients the amplitude of the sensory potential was diminished in the popliteal fos but not distal to the capitulum fibulae. However in one patient the difference in amplitude was $N$ probably due to inaccurate placement of tie recording electrode, because the long peroneat 1 muscle, ordinarily used to position the electrode, $z$ was completely denervated. In the two other patients the diminished amplitude might, 遇 fact, indicate block of conduction of sensog fibres at the level of the capitulum fibulae. Tha is, however, unlikely because there was no other electrophysiological evidence of a lesion of the nerve at the level of the capitulum fibulae, and because there was evidence of root compression (L4, surgically verified) in one and of mononeuritis multiplex in the other patient.

Shape of sensory potentials An increase in temporal dispersion of the potential recorded in $\frac{3}{\sqrt{3}}$ the popliteal fossa as compared with that recorded distally was evaluated only when amplitudes were $0 \cdot 1 \mu \mathrm{V}$ or greater. When amplitudes were lower, so many fibres had: ceased to conduct that an increase in temporal dispersion may remain hidden in noise.

In $80 \%$ of the nerves of patients from groups I and II the potentials recorded in the popliteal 음 fossa were dispersed to more than six compo- $\rightarrow$ nents, as compared with $10 \%$ in normal nerves (Fig. 8). The dispersion of the potential re- N corded distal to the capitulum fibulae was as in 
DISTAL TO

CAP. FIB.
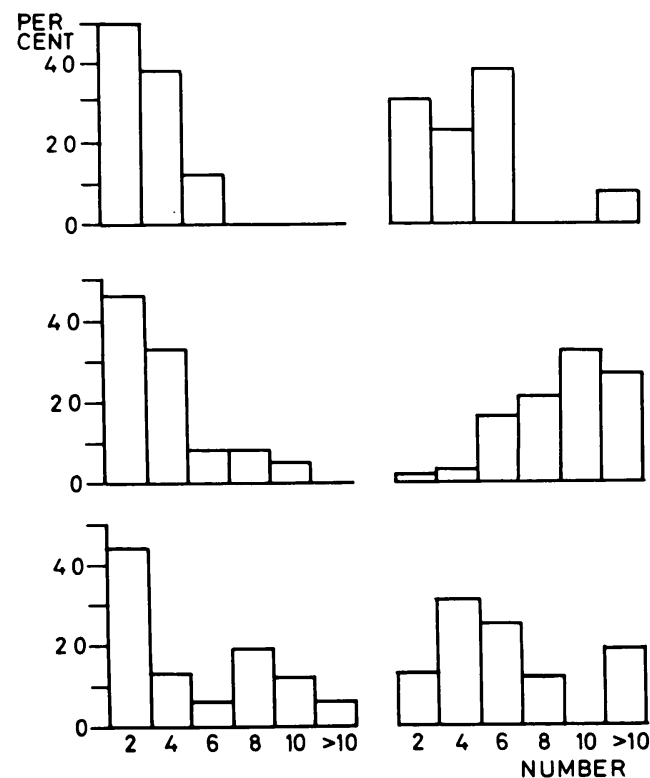

FIG. 8. Number of components of sensory potentials (abscissa) in peroneal palsy and in normal peroneal nerve. Ordinate: per cent of nerves. Left: recorded distal to the capitulum fibulae; right: in the popliteal fossa. Top: 16 normal nerves. Middle: 39 nerves from patients of groups I and II. Bottom: 16 nerves from patients of group III. Split-up of the sensory potentials into more than six components was considered abnormal.

normal nerve. In three of the five patients in whom the lesion could not be localized because of uniform slowing and of equally low amplitudes at both sites of recording, a potential with 10 to 12 components recorded in the popliteal fossa and a normal shape of the potential recorded distal to the capitulum fibulae pointed to a localized lesion.

In patients of group III, one-third of sensory potentials were dispersed to more components than normal both proximal and distal to the capitulum fibulae.

MOTOR CONDUCTION ACROSS AND DISTAL TO CAPITUlUM fIBUlaE Patients of groups $I$ and II In one-quarter of the patients of group I and half of the patients of group II a potential could

not be evoked in the extensor digitorum brevis muscle. In nine of the remaining 18 patients of group I and in five of 12 patients of group II slowing across and normal velocity along the segment of nerve distal to the capitulum fibulae localized the affection to the region of the capitulum (Figs 2, 4). Four patients of each group showed uniform slowing along the nerve. In three patients conduction along both segments was slowed but was more than $10 \mathrm{~m} / \mathrm{s}$ slower across the capitulum fibulae. Thus, motor conduction across the capitulum fibulae localized the lesion in one-third of 47 patients. In two patients with slowing of conduction across the capitulum fibulae, conduction velocity from the popliteal fossa to ankle was normal. Localized slowing along motor fibres occurred irrespective of whether the palsy was mild or severe but severe slowing was more frequent when the force of the anterior tibial and long peroneal

\section{SENSORY}

ANKI.E

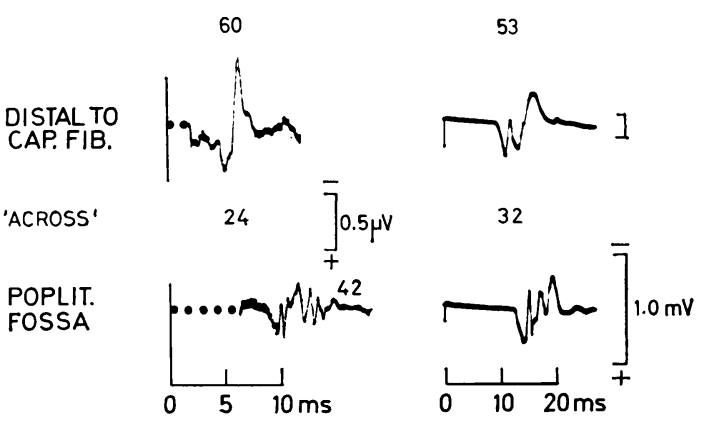

FIG. 9. Sensory and motor conduction along the peroneal nerve. Slowing in conduction 'ACROSS' was most severe along sensory fibres $(24 \mathrm{~m} / \mathrm{s})$; normal conduction along the segment of the nerve distal to the capitulum fibulae (sensory: $60 \mathrm{~m} / \mathrm{s}$; motor: $53 \mathrm{~m} / \mathrm{s}$ ). Conduction from the superior retinaculum to the popliteal fossa was $42 \mathrm{~m} / \mathrm{s}$. The sensory potentials were recorded by electronic averaging of 500 responses, in the popliteal fossa after a delay of $6 \mathrm{~ms}(\bullet \bullet \bullet)$. Patient 17622, 54 year old female, examined five weeks after the onset of peroneal palsy. The palsy was noticed after waking up in the morning. Clinical signs and symptoms were purely motor and confined to the right peroneal nerve (classified as group II). 
TABLE

ELECTROMYOGRAPHIC ABNORMALITIES IN PER CENT OF MUSCLES EXAMINED

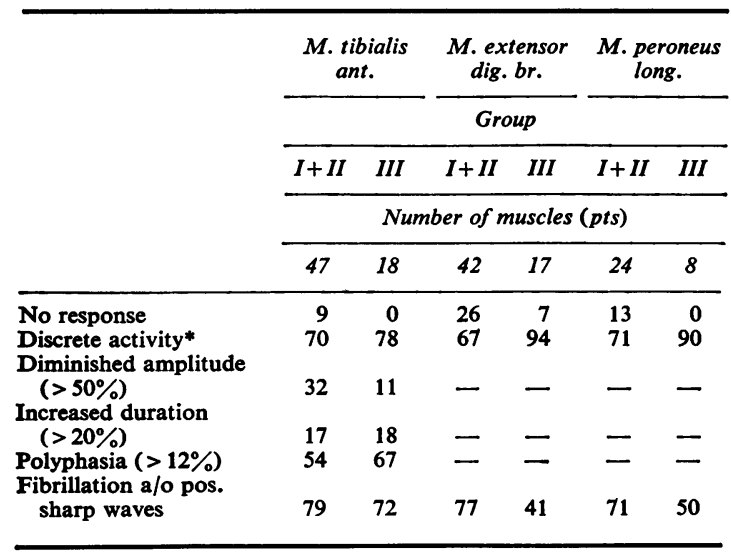

* During full effort.

muscles was graded as 3 or less. The localizing value of slowing across the capitulum fibulae with the response of the long peroneal and anterior tibial muscles as gauge is limited because it requires comparison with the distal conduction time. In normal subjects, the latency from distal to the capitulum fibulae to the long peroneal and anterior tibial muscle has a greater scatter than the conduction velocity $(25 \%$ as compared with $17 \%$ ). Motor conduction velocity across the capitulum fibulae in the fibres to the long peroneal and anterior tibial muscles was determined in $80 \%$ of the patients. In 29 of 38 conduction was slowed along this segment of the nerve, equally often along the nerve fibres to both muscles. Distal latency was normal in 12 of 29 patients with slowing across the capitulum fibulae, compatible with but not diagnostic of local slowing. Distal latency was prolonged in 17 patients, indicating either local slowing combined with loss of fast conducting nerve fibres or generalized slowing, as is, for example, seen in systemic neuropathy.

Of four patients with purely motor signs (Fig. 9) and symptoms and slowing along motor fibres across the capitulum fibulae, three had slowing of conduction along sensory fibres as well; in one patient sensory conduction velocity was borderline but $11 \mathrm{~m} / \mathrm{s}$ slower across than distal to the capitulum fibulae.
Patients of group III In 14 of 18 patients, in whom compression of the nerve in the region of the capitulum fibulae was unlikely, motor conduction velocity could be determined with the action potential of the extensor digitorum brevis muscle as gauge. In nine, conduction was normal and in five it was as slow across as distal to the capitulum fibulae. Conduction across the capitulum fibulae to the anterior tibial and long peroneal muscles was normal in 16 and slowed in two patients. The slowing was associated with prolonged distal latency. Thus, in none of the patients was there evidence of localized slowing in motor fibres.

AMPLITUDE OF RESPONSE EVOKED IN EXTENSOR DIGITORUM BREVIS MUSCLE A four times lower amplitude of the potential evoked by stimulation in the popliteal fossa than by stimulation distal to the capitulum fibulae indicated a localize lesion in six of 32 nerves from patients of group I and II. A difference of this order was never found in the 14 patients of group III or in 38 normal subjects.

LATENCY FROM ANKLE TO EXTENSOR DIGITORUNG Z BREVIS MUSCLE A prolonged latency was found in 10 of 36 nerves of the patients of groups I and II and in five of 14 nerves of patients of grou III. The increase in latency was moderate (usually less than $50 \%$ above the average of normal) and compatible with loss of fast conducting fibres.

ELECTROMYOGRAPHIC FINDINGS Abnormalities were similar in the patients of the three groups, except that voluntary activity was more apt to be absent in muscles of the patients of groups I and II than of group III (Table). Thus, the electromyographic findings gave no clue as to whether or not the peroneal palsy was due to local compression in the region of the capitulum fibulae. Clinically and electromyographically the extensor digitorum muscle was the most severely involved. It was completely denervated in one-quarter of the muscles of groups I and II. A pattern of discrete activity as evidence of loss of many motor units was seen in 70 to $90 \%$ of the muscles and fibrillation potentials and positive sharp waves in 40 to $80 \%$. The parameters of single motor unit potentials were analysed in the anterior 

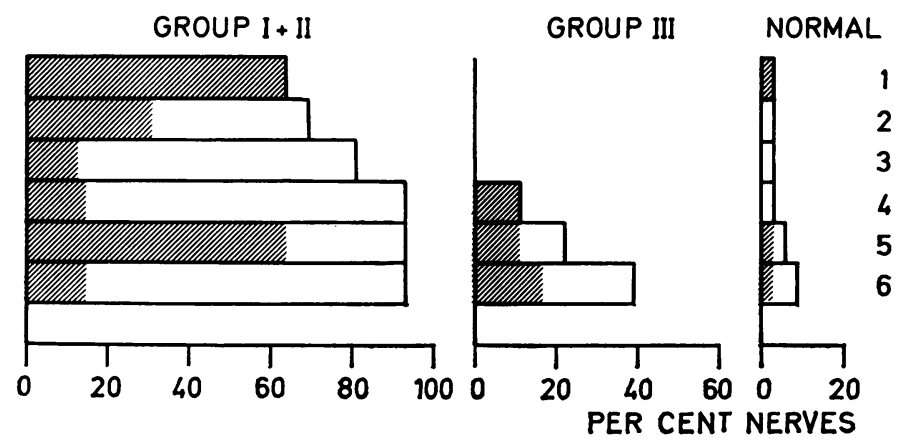

FIG. 10. Cumulative diagnostic yield of sensory and motor conduction in peroneal palsy. Left: 47 patients (groups I and II) with a history indicating or suggesting compression of the nerve at the capitulum fibulae. Middle: 18 patients (group III) without such history. Right: 33 normal subjects. (1) Column 1 (criterion 1) shows the percentage of patients in whom the lesion was localized by slowing in sensory conduction across the capitulum fibulae with normal conduction distal to it. Each subsequent column gives the diagnostic yield by each criterion over and above that obtained by the preceding criterion or criteria. The hatched areas indicate the percentage of patients whose lesion would have been localized by that criterion alone. The diagnostic criteria 2-6 are listed in the order of their incidence in group III (middle). (2) Motor conduction velocity across to the extensor digitorum brevis muscle slowed, conduction distal to the capitulum fibulae normal or slightly slowed but more than $10 \mathrm{~m} / \mathrm{s}$ faster than across. (3) Amplitude of motor response in the extensor digitorum brevis muscle at least four times greater when the stimulus was applied distal to the capitulum fibulae than in the popliteal fossa. (4) Sensory conduction velocity along both segments normal or slowed but slower across than distal to the capitulum fibulae by more than $10 \mathrm{~m} / \mathrm{s}$. (5) Motor conduction velocity across slowed to the anterior tibial and long peroneal muscle; distal latency normal. (6) Amplitude of the sensory potential recorded distal to the capitulum fibulae at least $2 \cdot 5$ times greater than when recorded in the popliteal fossa.

tibial muscle. Most prominent was an increase in the incidence of polyphasic potentials, probably indicating reinnervation. It was found in half to two-thirds of the muscles examined. The potential duration was increased in $20 \%$ and decreased in none.

\section{DISCUSSION}

In many patients in this study clinical signs and symptoms left doubt as to whether the peroneal palsy was due to involvement of a lumbar root or of the peripheral nerve. Electromyography may fail to distinguish between these two possibilities. Weakness and wasting due to root compression may be confined to muscles innervated by the peroneal nerve. Although root compression may be associated with paresis of other muscles than those innervated by the peroneal nerve, which muscles to investigate varies, since segmental innervation varies (Thage, 1965); and one-third of affected muscles do not show evidence of partial denervation - that is, fibrillation potentials and positive sharp waves (Buchthal, 1957).

In some patients the peroneal palsy was associated with mild clinical signs and symptoms of systemic neuropathy. Although electromyographic investigation allows recognition of widespread involvement, it does not establish whether in addition there is local impairment of conduction after pressure.

RECOGNITION OF DAMAGE OF NERVE LOCALIZED TO REGION OF CAPITULUM FIBULAE To demonstrate slowing in conduction along the segment of the peroneal nerve across the capitulum fibulae, it is necessary to confine measurements to this very segment. If a larger stretch of normal nerve is included, localized slowing may remain hidden, as demonstrated in lesions of the ulnar nerve at the cubital sulcus (Payan, 1969) and in the carpal tunnel syndrome (Buchthal and Rosenfalck, 1971a). In fact, in 10 of our patients with peroneal palsy and slowing along the segment of the nerve across the capitulum fibulae, sensory 
conduction was within the range of normal when determined from the superior retinaculum to the popliteal fossa. Conversely, if conduction is slowed from the superior retinaculum to the popliteal fossa or distal to it, this may or may not originate from a lesion localized to the region of the capitulum fibulae. It may be due to loss of fast conducting fibres, as in axonal neuropathy, or to more widespread demyelination. Not unless conduction across is significantly slowed as compared with conduction along the segment of the nerve distal to the capitulum fibulae does it indicate damage to the nerve which is primarily localized to the region of the capitulum.

DIAGNOSTIC YIELD OF CONDUCTION STUDIES Among 65 consecutive patients with peroneal palsy, sensory potentials were large enough to determine a conduction velocity proximal and distal to the capitulum fibulae in $95 \%$. Motor conduction velocity to the extensor digitorum brevis muscle could be determined in $70 \%$ of the patients.

The localizing value of slowing of conduction and of changes in sensory and motor responses is shown in Fig. 10 (hatched areas). Slowing of sensory conduction velocity across the capitulum fibulae with normal conduction velocity distal to capitulum fibulae gave the best diagnostic yield. Two-thirds of the patients with a history indicating or suggesting local compression at the capitulum fibulae exhibited this change, a criterion with no 'false positive' findings, since none of the patients of group III, without history or evidence of local compression, showed it (Fig. 10, middle). In one of the 33 normal subjects sensory conduction velocity was just outside the $95 \%$ confidence limit (Fig. 10, right).

Slowing across combined with normal conduction velocity distal to the capitulum fibulae was probably due to demyelination or incomplete remyelination in the region of the capitulum fibulae causing retardation in conduction or localized block of the fastest fibres or both. That the potential recorded distal to the capitulum fibulae was markedly diminished in two-thirds of the nerves examined indicates that there was, in addition, degeneration of many nerve fibres. Among these were the fastest conducting fibres as seen from the slight decrease in conduction velocity associated with a marked decrease in amplitude (Fig. 5).

The diagnostic yield of slowing across the capitulum fibulae along motor fibres ( $m$. extensor digitorum brevis) was only half that of slowing along sensory fibres. With the long peroneal or anterior tibial muscle as a gauge the diagnostic yield was apparently as good as slowing of sensory conduction. In fact, this criterion was less valuable than it seemed for reasons stated on p. 1210.

An increase in temporal dispersion proximal as compared with distal to the site of compression was observed in half the patients of groups I and II. It was of little diagnostic help because of similar findings in patients of group III.

Increased temporal dispersion and block of nerve fibres in the region of the capitulum fibulae should render the amplitude recorded in the fossa poplitea lower than that recorded distab to the capitulum fibulae. In fact, this criterion was of little diagnostic value because it was absent in many patients of group $\mathrm{I}$ and $\mathrm{II}_{\mathrm{O}}$ probably because the recording electrode was at some distance from sensory fibres. They arêे often located in a separate branch of the nerve af varying distance from motor fibres whose threshold was used to place the electrode neaf the nerve. This may also explain why the amplis. tude of the sensory potential was diminished in the popliteal fossa and normal distal to the capitulum fibulae in three patients of group III, although there was no other clinical or electrophysiological indication of a lesion of the peroneal nerve at the level of the capitulum fibulae.

In only $20 \%$ of the patients of groups I and II was the muscle action potential evoked in the extensor digitorum brevis muscle by a stimulus distal to the capitulum fibulae significantly larger than the response evoked by stimulation in the popliteal fossa.

In 23 of 24 patients of group II, in whom the history suggested compression of the peroneal nerve at the capitulum fibulae as the cause of the palsy, studies of sensory and motor conduction confirmed this suspicion. One patient had an alcoholic neuropathy with uniform slowing along all segments of the peroneal nerve.

The cumulative diagnostic yield of the different electrophysiological criteria to localize com- 
pression of capitulum fibulae is shown in Fig. 10. The sequence in which the criteria were listed was chosen from their incidence in patients of group III. Thus, motor conduction velocity across the capitulum fibulae (criterion 2) was slowed in $4 \%$ of the patients whose lesion was not localized by local slowing of sensory conduction (criterion 1) bringing the diagnostic yield from $64 \%$ to $68 \%$ of the patients. Criterion 3 (Fig. 10, motor response at least four times greater when the stimulus was applied distal to the capitulum fibulae than proximal to it) localized the lesion in an additional $2 \%$ of the patients whose lesion was not localized by slowing in conduction across the capitulum fibulae along sensory and motor fibres; and so forth. The last three criteria in Fig. 10 are of doubtful diagnostic value because they gave many false positive findings in patients of group III.

In four of the 47 patients the site of compression could not be localized: one patient had normal motor and sensory conduction throughout. He was examined five weeks after the onset of signs and symptoms when the paresis had recovered markedly. In three patients damage was so severe that a sensory potential could not be distinguished from noise and motor conduction could not localize the lesion.

Recently, Lovelace et al. (1973) reported recording of sensory potentials from the superficial peroneal nerve via surface electrodes using electronic averaging of 400 responses. In these recordings the amplitude of the potentials in normal nerve was one half of that which we have found by using a near-nerve electrode. Thus, if we had used surface electrodes we would have failed to detect a response in $30 \%$ of our patients with peroneal palsy localized to the region of the capitulum fibulae.

We wish to thank $\operatorname{Dr}$ A. Rosenfalck for helpful discussions and for the calculation of findings in normal nerves. The work was supported by grants from the Muscular Dystrophy Associations of America and from the Michaelsen Foundation, Copenhagen.

\section{REFERENCES}

Behse, F., and Buchthal, F. (1971). Normal sensory conduction in the nerves of the leg in man. Journal of Neurology, Neurosurgery, and Psychiatry, 34, 404-414.

Buchthal, F. (1957). An Introduction to Electromyography. Gyldendal: Copenhagen.

Buchthal, F., and Rosenfalck, A. (1966). Evoked action potentials and conduction velocity in human sensory nerves. Brain Research, 3, 1-122.

Buchthal, F., and Rosenfalck, A. (1971a). Sensory conduction from digit to palm and from palm to wrist in the carpal tunnel syndrome. Journal of Neurology, Neurosurgery, and Psychiatry, 34, 243-252.

Buchthal, F., and Rosenfalck, A. (1971b). Sensory potentials in polyneuropathy. Brain, 94, 241-262.

Buchthal, F., Rosenfalck, A., and Trojaborg, W. (1974). Electrophysiological findings in entrapment of the median nerve at wrist and elbow. Journal of Neurology, Neurosurgery, and Psychiatry, 37, 340-360.

Gassel, M. M., and Trojaborg, W. (1964). Clinical and electrophysiological study of the pattern of conduction times in the distribution of the sciatic nerve. Journal of Neurology, Neurosurgery, and Psychiatry, 27, 351-357.

Gilliatt, R. W., Goodman, H. V., and Willison, R. G. (1961) The recording of lateral popliteal nerve action potentials in man. Journal of Neurology, Neurosurgery, and Psychiatry, 24, 305-318.

Lovelace, R. E., Myers, S. J., and Zablow, L. (1973). Sensory conduction in peroneal and posterior tibial nerves using averaging techniques. Journal of Neurology, Neurosurgery, and Psychiatry, 36, 942-950.

Medical Research Council (1943). Aids to the Investigation of Peripheral Nerve Injuries. War Memorandum No. 7 H.M.S.O.: London.

Payan, J. (1969). Electrophysiological localization of ulnar nerve lesions. Journal of Neurology, Neurosurgery, and Psychiatry, 32, 208-220.

Thage, O. (1965). The myotomes L2-S2 in man. Acta Neurologica Scandinavica, 41, Suppl. 13, 241-243.

Trojaborg, W. (1970). Rate of recovery in motor and sensory fibres of the radial nerve: clinical and electrophysiological aspects. Journal of Neurology, Neurosurgery, and Psychiatry, 33, 625-638.

Wagner, A. L., and Buchthal, F. (1972). Motor and sensory conduction in infancy and childhood: reappraisal. Developmental Medicine and Child Neurology, 14, 189-216. 